\title{
Hand-Schuller-Christian disease
}

\author{
Akhlaque Hossain Khan, Md. Rezaul Amin, Bazlul Karim and Narendra Shalike
}

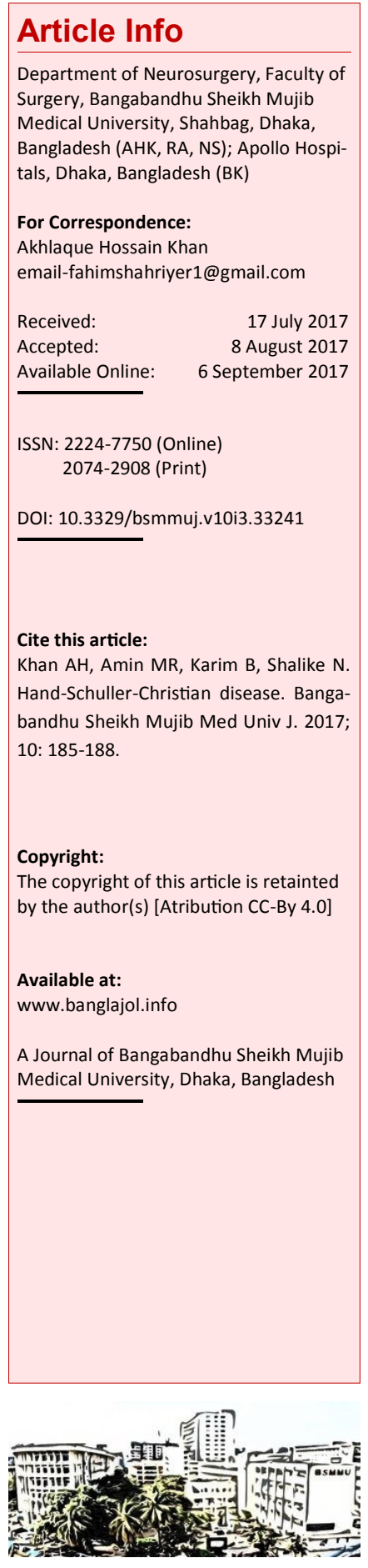

\section{Abstract}

Hand-Schuller-Christian disease (HSC) is a rare disease of unknown cause. We report a case of Hand-Schuller-Christian disease with a solitary swelling over left parieto-occipital region of scalp, and increased thirst with polyuria. Prompt diagnosis and treatment of the disease will improve the life expectancy.

\section{Introduction}

Hand-Schuller-Christian disease (HSC) is a rare disease of unknown cause. 1 It is one of the three subtypes of Langerhans cells histiocytosis (LCH) formerly called as Histiocytosis X. LCH is a rare proliferative disorder of the bone marrow derived antigen presenting cells of the dendritic cell line, also known as Langerhans cell. This disease is a spectrum of three subtypes including eosinophilic granuloma, HSC and Letterer-Siwe disease.? The classical triad of HSC- exophthalmos, diabetes insipid-dus, and calvarial lytic lesions - is seen only in one-third patients. Skull is the common site involved and with $50 \%$ cases reporting with diabetes insipiddus. HSC has an incidence of $0.18 / 100,000$, usually affects young children, more commonly seen in boys, with male:female ratio of approximately $2: 1 . \underline{3}$

\section{Case Report}

A 7 year old boy from Patuakhali, Bangladesh presented with a solitary swelling over left parieto-occipital region of scalp over 2 years, increased thirst with polyuria for 6 months (Figure 1). The swelling over the scalp was insidious in onset, progressively increasing in size (5 $\times 4 \mathrm{~cm}$ in size at the moment), nontender, firm in consistency with ill-defined margin, free from the overlying skin but fixed with the underlying scalp layers. He complained of excessive thirst, having to take up to 7-8 liters of water per day, which was associated with polyuria, including nocturia. He was hemodynamically stable and not dehydrated and there was no evidence of other systemic involvement.

Investigations revealed normal hemogram,

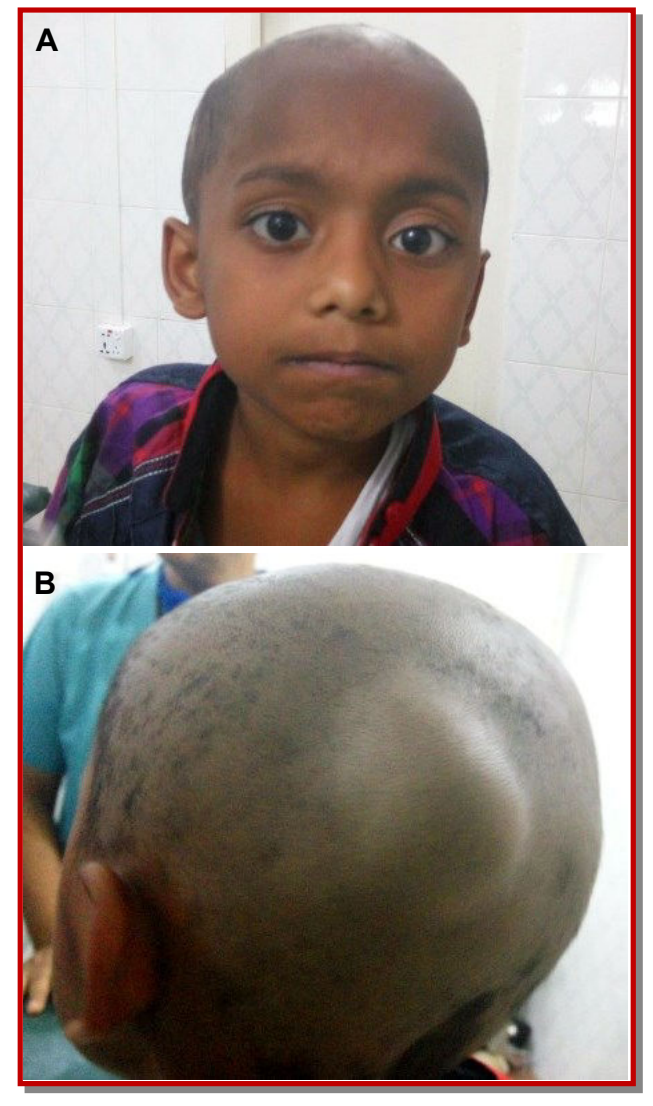

Figure 1: A) Front view of the head showing no features of exophthalmos; (B) Back view showing swelling over the scalp $5^{*} 4 \mathrm{~cm}$ in size, non-tender, firm in consistency with ill-defined margin, free from the overlying skin but fixed with the underlying scalp layers

urea, creatinine, and normal blood glucose levels, effectively ruling out diabetes mellitus. ESR was $25 \mathrm{~mm}$ in $1^{\text {st }}$ hour. Serum electrolytes revealed hypernatremia ( $\mathrm{Na}+$ level $155 \mathrm{mEq}$ / 

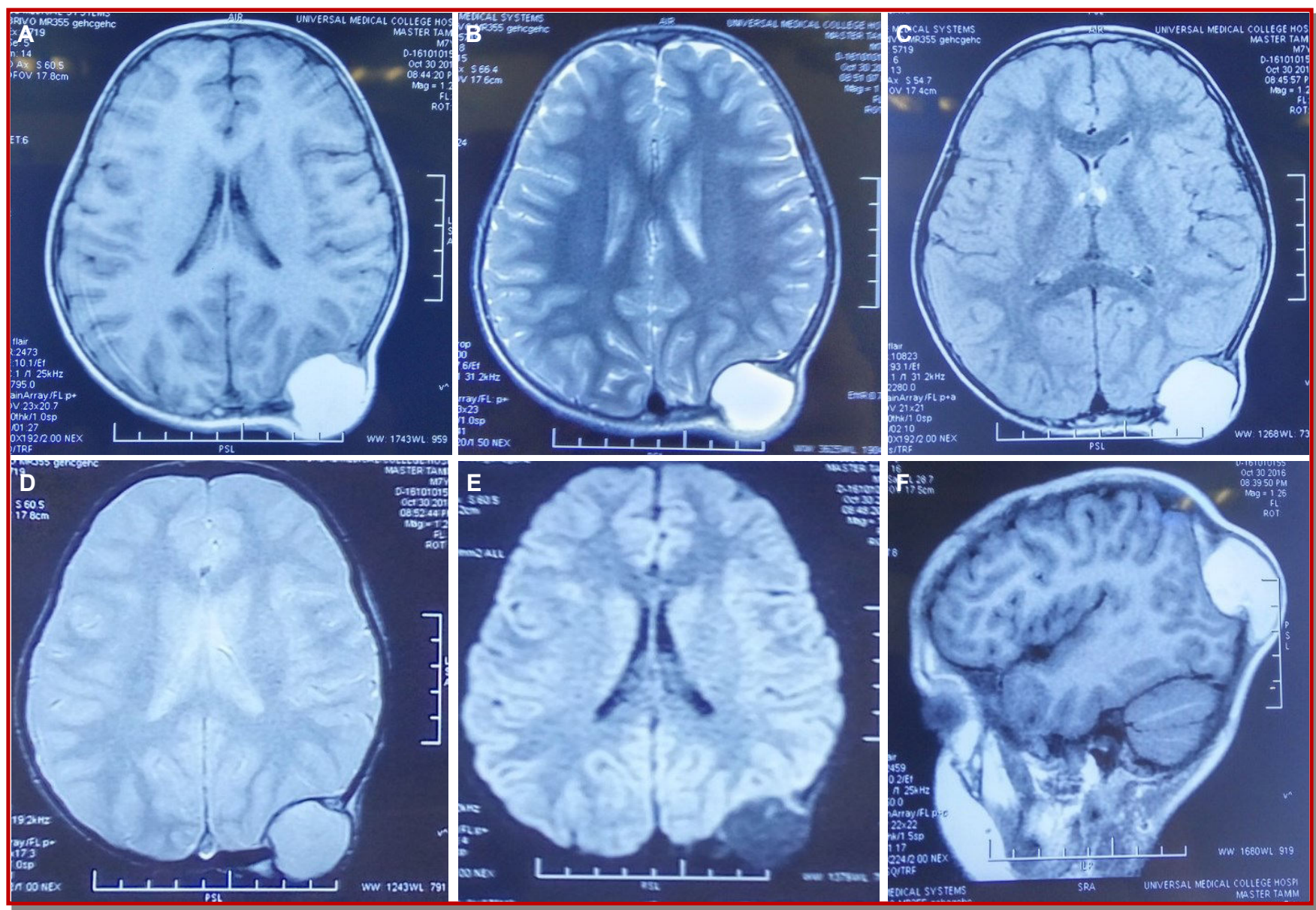

Figure 2: MRI of brain showed a fairly large $(5.0 \times 4.2 \times 3.9 \mathrm{~cm})$ mass lesion of diploic space having intra- and extra-cranial segments, smoothly outlined signal intensity change area is seen on the left side of parieto-occipital region, which is highly homogenously hyperintense in all pulse sequences (T1, T2 weighted image, FLAIR), GRe showing no blooming. DW images showed no definite areas of restriction, except tiny ill-defined areas of restriction

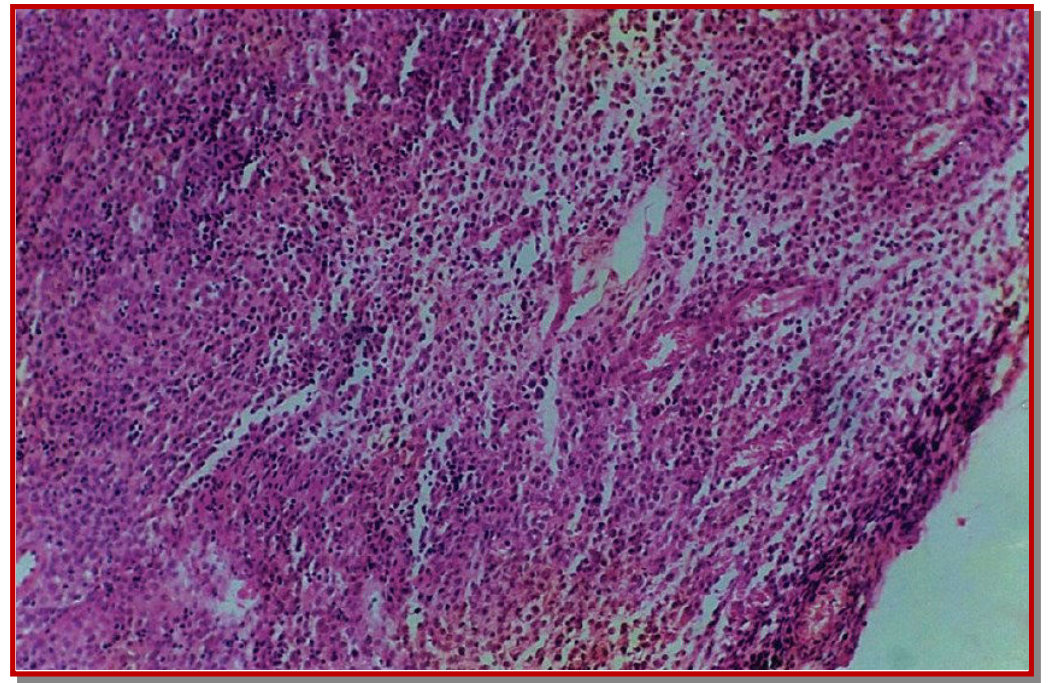

Figure 3: Hematoxylin and eosin-stained section shows numerous histiocyte-like cells, eosinophils, and lymphocytes scattered in a loose connective tissue stroma
L). The serum osmolarity was $332 \mathrm{mosm} / \mathrm{L}$. The urine osmolarity was $210 \mathrm{mosm} / \mathrm{L}$ and specific gravity of urine was found to be 1.001, suggestive of diabetes insipidus.

MRI of brain showed a fairly large $(5.0 \times 4.2 \times 3.9$ $\mathrm{cm}$ ) mass lesion of diploic space having intra and extra cranial segments, smoothly outlined signal intensity change area is seen on the left side of parieto-occipital region, which is highly homogenously hyper-intense in all pulse sequences (T1, T2 weighted image, FLAIR), GRe showing no blooming. DW images showed no definite areas of restriction, except tiny ill-defined areas of restriction. Large bone destruction on that area and also in the floor of left anterior and middle cranial fossa (Figure 2)

He underwent left parieto-occipital craniotomy and removal of the mass done under general anesthesia. Histopathology report suggested Langerhans cell histiocytosis (Figure 3). He was then referred to the Oncology Department for further management. 


\section{Discussion}

HSC is a rare entity comprising of exophthalmos, diabetes insipidus and geographical map skull. However, the first case described by Hand $\underline{4}$ in 1893 had bronzed skin, hepatosplenomegaly and poor development, besides exophthalmos and geographic map skull. Schuller-5 (1915) and Christians, (1919) had called in attention to this triad. It was Rowland7 (1929) who gave histological description of this lesion in different organs while Green and Farber-8 (1942) demonstrated that eosinophilic granuloma of bone, Hand Schuller Christian disease and Letterer-Siwe Syndrome have the same basic pathology.

HSC may involve any bone, but preferred sites are the skull, mandible, spine and long bones. The lesions may be well defined or poorly defined with or without associated sclerotic borders. A variable amount of periosteal reaction can be present, ranging from a thick solid type to lamellated. 2

In the skull, lesions usually have sharply defined borders with uneven involvement of the inner and outer table (bevelled edge sign, hole within hole). At the centre of the lytic process a button sequestrum may appear. Large lesions give the appearance of geographic skull. In the mandible and maxilla, bone destruction may produce the appearance of floating teeth. $.10,11$

Radiographically, LCH lacks pathognomonic characteristics and may mimic a wide spectrum of lesions such as radicular cysts, periodontal disease, osteomyelitis and malignancies. Most often, lesions appear as sharply punchedoutradiolucencies. $\underline{12}$

In our case, he had a swelling over the scalp of size $5^{*} 4 \mathrm{~cm}$, non-tender, firm in consistency with illdefined margin, free from the overlying skin but fixed with the underlying scalp layers. MRI of brain showed a fairly large $(5.0 \times 4.2 \times 3.9 \mathrm{~cm})$ mass lesion of diploic space having intra and extra cranial segments, smoothly outlined signal intensity change area is seen on the left side of parietooccipital region, which is highly homogenously hyper-intense in all pulse sequences.

Central diabetes insipidus (CDI) is associated in 15$25 \%$ cases of Histiocytosis $X$, about half of whom manifest CDI early in the disease. 13,14 CDI may be associated with pituitary stalk thickening on imaging, although not present in all cases. 75\% of cases with CDI go on to disease free survival but require hormonal replacement. $\underline{13}$

Unilateral or bilateral ocular and peri-orbital involvement resulting in exophthalmos, as well as scalp disease has also been reported. $\underline{14}$

In our case, he had the clinical features and the investigation reports suggestive of diabetes insipidus. But he didn't have features of exophthalmos.
The classical triad of HSC (exophthalmos, diabetes insipidus, and calvarial lytic lesions) is seen only in one-third patients.

$\mathrm{LCH}$ is usually a self-limiting disease. In the absence of organ dysfunction, patients with either localized or multifocal LCH have an excellent prognosis. $\underline{15}$ Treatment of histiocytosis $X$ may involve chemotherapy, radiotherapy or curettage surgery of the skull lesions. -3 Chemotherapy coupled with radiation to localized bony lesions and supportive measures are useful in treatment, there being no unified therapeutic measures. $\underline{16}$ Our patient underwent Left parieto-occipital craniotomy and removal of the mass done under general anesthesia. Histopathology report suggested Langerhans cell histiocytosis. He was continued on DDAVP nasal spray (desmopressin acetate nasalspray) and referred to Oncology Department for the further management.

\section{Conclusion}

Our case report highlights the importance of multi modality approach including clinical examination, serum biochemistry, radiological imaging and immunohistochemistry in giving a specific diagnosis to this condition. Prompt diagnosis and treatment of the disease will improve the life expectancy.

\section{Conflict of interest}

Authors declare no conflict of interest.

\section{References}

1. Melkundi SS, Govindaraju BT, Deepika KP, Giri JK, Sankuri R. Hand-Schuller-Christian disease in twins: A very rare case. J Evolution Med Dent Sci. 2014; 3: 15344-52.

2. Kumar BS, Gowda S, Gowda A, Gopal MG, Ramesh M. A case report of Hand-SchullerChristian Disease. J Evolution Med Dent Sci. 2013; 2: 8255-59.

3. Das A, Cader FA. A young male presenting with polyuria and unilateral exophthalmos. J Bangladesh Coll Phys Surg. 2015; 32: 241-43.

4. Hand A. General tuberculosis. Trans Path Soc Philadelphia. 1893; 16: 282.

5. Schuller A. Uebereigenartigeschadeldefekte in Jugandalter. Fortschr. a. d. Geb. d. Roentgenstrahlen, 23: 12, 1915-16.

6. Christian HA. Defects in membranous bones, exophthalmos and diabetes insipidus: An unusual syndrome of dyspituitarism- a clinical study. Contrib Med Biol Res. 1919; 1: 390. (Hoeber, New 
York).

7. Rowland RS. Christian's syndrome and lipoid-cell hyperplasia of the reticuloendothelial system. Ann Int Med. 1929; 2: 1277-99.

8. Green WT, Farber S. Eosinophilic or solitary granuloma of bone. J Bone Joint Surg. 1942; 24: 499526.

9. Kransdorf MJ, Jelinek JS, Moser RP Jr. Imaging of soft tissue tumors. Radiol Clin North Am. 1993; 31: 359-72.

10. David R, Oria RA, Kumar R, Singleton EB, Lindell MM, Shirkhoda A, Madewell JE. Radiologic features of eosinophilic granuloma of bone. AJR. 1989; 153: 1021-26.

11. Marioni G, De Filippis C, Stramare R, et al. Langerhans' cell histiocytosis: Temporal bone involvement. J Laryngol Otol. 2001; 115: 839.

12. Ardekian L, Peled M, Rosen D, Rachimel A, Abu el-
Naaj I, Laufer D. Clinical and radiographic features of eosinophilic granuloma in the jaws: Review of 41 lesions treated by surgery and low-dose radiotherapy. Oral Surg Oral Med Oral Pathol Oral Radiol Endod. 1999; 87: 238-42.

13. Shah AK, Solanki RN, Mahajan A. Hand Schuller Christian disease causing diabetes insipidus. Indian J Radiol Imaging. 2003; 13: 297-300.

14. Tebbi CK. Histiocytosis: Clinical presentation [online]. http://emedicine.medscape.com/ article/958026-clinical\#a0217 (Accessed on 27.09.2013).

15. Mayer JS, Harty MP, Mahboubi S, et al. Langerhans cell histiocytosis: Presentation and evaluation of radiological findings with clinical correlation. Radiographics 1995; 15: 1135-46.

16. McClelland J, Pritchard J, Chu AC. Current controversies. Hematol Oncol Clin North Am. 1987; 1: 147. 